\title{
GIn27Glu polymorphism in the beta2 adrenergic receptor gene and lipid metabolism during exercise in obese women
}

\author{
T Macho-Azcarate ${ }^{1}$, A Marti $^{1}$, A González $^{2}, \mathrm{JA} \mathrm{Martinez}^{1 \star}$ and J Ibañez ${ }^{3}$ \\ ${ }^{1}$ Department of Physiology and Nutrition, University of Navarra, Pamplona, Spain; ${ }^{2}$ Biochemistry Department, University Clinic, \\ Pamplona, Spain; and ${ }^{3}$ Centro de Investigación y Medicina del Deporte, Gobierno de Navarra, Pamplona, Spain
}

BACKGROUND: The Glu27Glu genotype in the beta-2-adrenergic receptor (ADRB2) is associated with fat mass, body mass index and obesity in females. In our population, we previously found an association of higher body mass index (BMI) among women who reported more physical activity and carried the Glu27 allele as compared to non carriers with the same level of activity.

OBJECTIVE: To examine the lipid metabolism differences, both at rest and during submaximal exercise in ADRB2 Glu27Glu vs Gln27Gln obese women.

SUBJECTS: Eight obese women with the Glu27Glu genotype (age, $43 \pm 5 \mathrm{y}$; body mass index (BMI), $31.7 \pm 0.9 \mathrm{~kg} / \mathrm{m}^{2}$; percentage fat mass, $42.0 \pm 1.3$; WHR, $0.83 \pm 0.02$; and $\mathrm{VO}_{2 \max }, 21.6 \pm 0.9 \mathrm{ml} / \mathrm{kg} / \mathrm{min}$ ) were compared with seven obese women with the Gln27Gln genotype (age, $43 \pm 5 \mathrm{y} ; \mathrm{BMI}, 33.9 \pm 1.3 \mathrm{~kg} / \mathrm{m}^{2}$; percentage fat mass, $41.6 \pm 1.2 ; \mathrm{WHR}, 0.83 \pm 0.02$; and $\left.\mathrm{VO}_{2 \text { max }}, 20.6 \pm 0.8 \mathrm{ml} / \mathrm{kg} / \mathrm{min}\right)$.

MEASUREMENTS: The ADRB2 polymorphism was identified by PCR-RFLP. Respiratory quotient was determined by indirect calorimetry at baseline, during $1 \mathrm{~h}$ of walking on a treadmill and $1 \mathrm{~h}$ after the exercise. Plasma triglycerides, glycerol, FFA, hydroxybutyrate, glucose and lactate were assayed by spectrophotometric methods. Insulin, leptin and progesterone were measured by radioimmunoassay. Adrenaline and noradrenaline were quantified by high performance liquid chromatography. RESULTS: The ADRB2 Glu27Glu subjects had lower plasma glycerol $(P=0.047)$ and lower hydroxybutyrate $(P=0.001)$ throughout the study than the Gln27GIn group. Plasma triglycerides $(P=0.001)$, lactate $(P<0.05)$ and serum insulin $(P<0.05)$ remained higher in the Glu27Glu group vs the Gln27Gln group. The respiratory quotient (RQ) was higher in the Glu27Glu obese women along the study $(P=0.046)$, and fat oxidation was significantly lower in this group during the recovery $(P=0.048)$. The other variables did not differ statistically between groups.

CONCLUSION: These data suggest that both lipolysis and fat oxidation promoted by an acute submaximal exercise intervention could be blunted in the polymorphic ADRB2 Glu27Glu group of our female obese population.

International Journal of Obesity (2002) 26, 1434-1441. doi:10.1038/sj.ijo.0802129

Keywords: beta2 adrenoceptor; Gln27Glu polymorphism; obesity; exercise; women

\section{Introduction}

The $\beta 2$-adrenergic receptor (ADRB2) is a major lipolytic receptor in human fat cells. ${ }^{1}$ Although adipose tissue contains $\beta 1$-, $\beta 2$ - and $\beta 3$-adrenoceptors, obesity-induced catecholamine resistance appears primarily because of defects in

*Correspondence: JA Martinez, Department of Physiology and Nutrition, University of Navarra, 31008 Pamplona, Spain.

E-mail: jalfmtz@unav.es

Received 28 February 2002; revised 14 May 2002;

accepted 27 May 2002 $\beta 2$-stimulation. ${ }^{2,3}$ Furthermore, it has been suggested that ADRB2 is responsible for the impaired effects in thermogenesis, lipid oxidation and lipolysis in the obese in vivo. ${ }^{4}$

Several polymorphisms have been described ${ }^{5}$ both in the coding region of the ADRB2 gene (Arg16Gly, Gln27Gln, Thr164Ile) and in the $5^{\prime}$ leader cistron (Cys19Arg), that result in significantly changed functions of this receptor. ${ }^{6-8}$ Indeed, polymorphisms in the coding region showed an ADRB2 functional impairment in recombinant cells. ${ }^{6,9}$

Available data raise arguments for ${ }^{10-19}$ and against ${ }^{20-22}$ the association of obesity with the Gln27Glu polymorphism. In a Swedish population, ${ }^{11}$ Glu27Glu women have an 
average fat mass excess of $20 \mathrm{~kg}$ and $\sim 50 \%$ larger fat cells than controls. In this study, the Gln $27 \mathrm{Glu}$ polymorphism was markedly associated with obesity with a relative risk for obesity of $\sim 7$ and an odds ratio of $\sim 10$. Interestingly, Meirhaeghe et al have reported that polymorphisms in the ADRB2 gene influence the effects of physical activity in the determination of the level of $\mathrm{FFA}^{23}$ and of the body mass index (BMI). ${ }^{16}$ Thus, Gln27Glu polymorphism has been strongly associated with obesity in patients reporting no physical activity, and physical activity might counterbalance the effect of a genetic predisposition to increase body weight, body fat and obesity. ${ }^{16}$ Indeed, Glu27Glu Caucasian postmenopausal women had higher weight, BMI and fat mass with a lower maximal $\mathrm{O}_{2}$ consumption than the other ADRB2 genotypes. ${ }^{24}$ In our population, we previously found an association of higher BMI among women who reported more physical activity and carried the Glu27 allele as compared with non-carriers. ${ }^{25}$ This suggests that women bearing the Glu27 allele do not benefit equally from exercise and appear to be more resistant to weight loss when reporting high levels of physical activity.

Walking is often included in studies of exercise in relation to disease, ${ }^{26}$ but has seldom been specifically tested in relation to obesity and gene variants. ${ }^{23,27}$ During low-intensity exercise $\left(25-40 \% \mathrm{VO}_{2 \mathrm{max}}\right)$, such as walking, there is an increased release of FFA into the circulation as a product of triacylglycerol hydrolysis in the adipose tissue. ${ }^{28}$ This lipolysis is a key step in the metabolic process leading to the decrease of fat mass and is mainly regulated by catecholamines and insulin. ${ }^{29}$

Therefore, the present study was designed to examine the lipid metabolism differences, both at rest and during submaximal exercise in ADRB2 Glu27Glu vs Gln27Gln obese women.

\section{Methods}

\section{Subjects}

In our study, eight Glu27Glu obese women were compared with seven Gln27Gln obese women, matched by age, BMI, percentage of body fat mass, waist-to-hip ratio and peak oxygen consumption (Table 1). These groups were selected after having genotyped 129 obese subjects $\left(\mathrm{BMI}>30 \mathrm{~kg} / \mathrm{m}^{2}\right.$, age 20-60) from the Hospital of Navarra, Spain. Diabetes mellitus, hypothyroidism, hepatic or renal dysfunction, hypertension (systolic pressure over $160 \mathrm{mmHg}$ and/or diastolic pressure over $90 \mathrm{mmHg}$, measured on two different occasions), cardiopathies, asthma, bronchitis, EPOC, bone or joint disturbances, alcohol or drug addiction and smoking were considered exclusion criteria. The study was approved by the ethical committee of Navarra and informed consent was signed by all volunteers before the study.

\section{Analysis of PCR-RFLP}

Genomic DNA was extracted from leukocytes in samples of whole blood by proteinase $\mathrm{K}$ digestion followed by phenol/ chloroform extraction. PCR amplification was performed on a Perkin Elmer, Gene Amp PCR system 2400, Applied Biosystems, Foster City, CA, USA.

The $30 \mu \mathrm{l}$ reaction volume contained 150-250 ng DNA, $0.2 \mathrm{mM}$ of each deoxynunucleoside triphosphate, $1 \times$ buffer (10 mM Tris $-\mathrm{HCl}, 1.5 \mathrm{mM} \mathrm{MgCl}_{2}, 5 \mathrm{mM} \mathrm{KCl}, \mathrm{pH} 8.3$ ), 20 pmol of each primer, and $1 \mathrm{U}$ of Biotaq DNA Polymerase. The following primers were used to amplify a 310 base pair (bp) fragment: 5'-CCGCCGTGGGTCCGCC-3' (forward) and 5'-CCATGACCAGATCAGCAC-3' (reverse). The PCR program was a modification of Large et al: ${ }^{11}$ each step of the cycle lasted $30 \mathrm{~s}$ and the annealing temperature was $64^{\circ} \mathrm{C}$. The 310 bp PCR product was digested with 5 units of ItaI or with its

Table 1 Anthropometric, food intake, fitness and basal characteristics of subjects participating in the submaximal exercise study

\begin{tabular}{|c|c|c|c|c|}
\hline Characteristic & Glu27Glu $(\mathrm{n}=8)$ & $G \ln 27 G \ln (\mathrm{n}=7)$ & Statistical analysis & $P$ \\
\hline Age $(y)$ & $43(5)$ & $43(5)$ & $\mathrm{T}$ & 0.901 \\
\hline Height (m) & $1.59(0.02)$ & $1.59(0.03)$ & $\mathrm{T}$ & 0.948 \\
\hline $\operatorname{BMI}\left(\mathrm{kg} / \mathrm{m}^{2}\right)$ & $31.7(0.9)$ & $33.9(1.3)$ & $\mathrm{T}$ & 0.175 \\
\hline Percentage fat mass & $42.0(1.3)$ & $41.6(1.2)$ & $\mathrm{T}$ & 0.842 \\
\hline Fat mass $(\mathrm{kg})$ & $33.6(1.8)$ & $34.4(1.3)$ & $\mathrm{T}$ & 0.772 \\
\hline Waist $(\mathrm{cm})$ & $94.19(2.9)$ & $97.5(3.3)$ & $\mathrm{T}$ & 0.467 \\
\hline WHR & $0.83(0.02)$ & $0.83(0.02)$ & $\mathrm{U}$ & 0.755 \\
\hline Caloric intake $(\mathrm{kJ})$ & $6835.7(502.3)$ & $7388.3(569.3)$ & $\mathrm{T}$ & 0.478 \\
\hline Percentage fat intake & $34(4)$ & $32(2)$ & $\mathrm{T}$ & 0.724 \\
\hline Percentage $\mathrm{CHO}$ & $49(5)$ & $52(2)$ & $\mathrm{T}$ & 0.676 \\
\hline $\mathrm{VO}_{2 \max }(\mathrm{ml} / \mathrm{kg} / \mathrm{min})$ & $21.6(0.9)$ & $20.6(0.8)$ & $\mathrm{T}$ & 0.613 \\
\hline Percentage $\mathrm{VO}_{2 \max }$ & $32.3(1.1)$ & $35.6(1.4)$ & $\mathrm{T}$ & 0.121 \\
\hline Maximal HR (beat/min) & $170(5)$ & $168(3)$ & $\mathrm{T}$ & 0.750 \\
\hline Maximal RQ & $1.34(0.05)$ & $1.31(0.02)$ & $\mathrm{T}$ & 0.612 \\
\hline Progesterone (ng/ml) & $0.39(0.07)$ & $0.44(0.08)$ & $\mathrm{T}$ & 0.656 \\
\hline
\end{tabular}

Values are means (s.e.m.). BMI, body mass index; WHR, waist to hip ratio; $\mathrm{CHO}$, carbohydrate; $\mathrm{VO}_{2 \mathrm{max}}, \mathrm{peak}$ oxygen consumption; percentage $\mathrm{VO}_{2 \max }$, percentage of peak oxygen consumption developed in the submaximal exercise study. T, Student's t-test. U, Mann-Whitney's U-test. 
isoschizomer Fnu4HI overnight. The obtained fragments sized 84 and 226 bp for the Glu27 allele and 84, 55 and $171 \mathrm{bp}$ for the Gln27 allele. They were observed on an ethydium bromide stained $1.35 \%$ agarose gel, under UV illumination.

\section{Peak oxygen consumption test}

Subjects arrived at 8.00 am to the hospital unit and weight, height, waist circumference and hip circumference were measured to calculate BMI and waist-to-hip ratio (WHR). Body fat (BF) was measured by bioimpedance (TANITA TBF-300, Bio Logica, Japan). All participants were studied with a multistage exercise treadmill test according to the Bruce protocol $^{30}$ using a breath-by-breath MMC Horizon System 4400 tc, SensorMedics, Anaheim, CA, USA. Exhaustion was considered when at least three of the four following criteria were fulfilled: (a) heart rate (HR) over $85 \%$ of maximal HR calculated by the age predicted formula; (b) respiratory exchange ratio (RER) over 1.2 ; (c) a plateau in $\mathrm{O}_{2}$ consumption $\left(\mathrm{VO}_{2}\right)$, despite an increase in workload, and (d) an inability of the subject to continue despite urging by the testing staff. Data from the $\mathrm{VO}_{2 \max }$ test were used to screen for evidence of cardiovascular disease and therefore exclude them from the study, given that obese patients have an increased risk of developing such diseases. ${ }^{31,32}$

\section{Submaximal test}

Approximately 20 days after the $\mathrm{VO}_{2 \max }$ test, volunteers arrived at $8.00 \mathrm{am}$ at the hospital unit by car or public transport. They were requested to avoid strenuous physical exercise $36-48 \mathrm{~h}$ before the study. Eumenorrheic women came during the follicular phase of their menstrual cycle (days 6-10 after menstruation began) and serum progesterone was drawn to ensure that they were in the follicular state. ${ }^{33}$ The last meal before the study consisted of $100 \mathrm{~g}$ of pasta with $40 \mathrm{~g}$ of olive oil-tomato sauce and $125 \mathrm{~g}$ of yoghurt. Urine was collected in the basal state after an overnight fast (12h) and at the end of the study. The anthropometrical measurements were repeated to ensure that weight had not changed since the $\mathrm{VO}_{2 \max }$ test. Volunteers completed a $24 \mathrm{~h}$ food intake recall of the day before the testing session. An intravenous catheter was inserted in the right arm and all subjects rested undisturbed during $40 \mathrm{~min}$ before the first sample of blood was extracted and every 30 min a new blood sample was drawn until the end of the study. Immediately following the first blood sample extraction, all participants walked on the mentioned treadmill for 60 min at a constant speed that elicited $30-35 \%$ of their individual $\mathrm{VO}_{2 \max }$, obtained in the previous intervention.

The treadmill speed or walking pace $(\mathrm{km} / \mathrm{h})$ was calculated taking into account McArdle's tables, which relate energy expenditure $(\mathrm{kJ} / \mathrm{min})$, speed $(\mathrm{km} / \mathrm{h})$ and body mass $(\mathrm{kg}) .^{34}$

Samples of breath gases were collected $30 \mathrm{~min}$ before, during, and $60 \mathrm{~min}$ after the exercise. Basal urine urea was used to estimate nitrogen excretion and thus to calculate basal protein oxidation. Postexercise urine urea was used to estimate protein oxidation both during the exercise and the postexercise period (urea $(\mathrm{mg} / \mathrm{dl}) \times 0.0055=$ urinary nitrogen $(\mathrm{g} / \mathrm{l})$ ). After correction for protein oxidation, carbohydrate and lipid oxidation rates were calculated from $\mathrm{O}_{2}$ consumption and $\mathrm{CO}_{2}$ production as described by Ferrannini. ${ }^{35}$ For carbohydrate oxidation, the glycogen formula was employed as roughly three-quarters of plasma glucose turnover is derived from liver glycogenolysis after an overnight fast. ${ }^{35,36}$ The $24 \mathrm{~h}$ recall food intake was analyzed with a computerized program by a trained nutritionist on a computerized program (Medisystem, SanoCare, Madrid, Spain). ${ }^{37}$

\section{Analytical methods}

Plasma glucose, triglycerides, glycerol, FFA, D-3-hydroxybutyrate and urine urea were determined with a Cobas Mira S apparatus, by spectrophotometric methods. Plasma lactate was placed in a fluoride EDTA tube and was determined in the same apparatus. Serum progesterone and insulin (CoatA-Count, Progesterone and Insulin, respectively, DPC, Los Angeles, CA, USA), as well as leptin (Human Leptin IRMA, DSL, Webster, TX, USA) were measured by radioimmunoassay (DPC Gambyt, Los Angeles, CA, USA). Plasma noradrenaline and adrenaline levels were determined by HPLC, according to the method described by Boomsma et al. ${ }^{38}$

\section{Data analysis}

All data are presented as the mean (s.e.m.). Variables listed in Table 1 and fat oxidation were analyzed by either unpaired Student's $t$-test or Mann-Whitney's $U$-test, as appropriate, depending on normality test results. A chi-square test was used to analyze the allelic distribution. Time-group interaction, time-effect and differences between groups were analyzed with a repeated measures factorial ANOVA (RMFA) in both biochemical and RQ values. When ANOVA for time was significant, post-hoc Tukey B test was performed. When ANOVA for group was significant, unpaired Student's $t$-test was performed. ${ }^{4}$ The SPSS 7.5 version for WINDOWS was used for the statistical analysis.

\section{Results}

\section{Population genotype}

Allelic frequency of the Glu27 allele was 0.43, and did not differ from other genotyped obese Caucasian populations. This obese population was in Hardy - Weinberg equilibrium $\left(\chi^{2}=0.58212\right.$, d.f. $\left.=1, P=0.58\right)$. The frequencies of genotypes were 0.325 in Gln27Gln, 0.185 in Glu27Glu and 0.49 in Gln27Glu. The selected Glu27Glu obese women $(n=8)$ were compared with other Gln27Gln obese female subjects $(n=7)$, matched by age, BMI, fat mass, WHR and $\mathrm{VO}_{2 \max }$. The two groups did not differ statistically (Table 1) in any of the former criteria $(P>0.10)$. 


\section{Metabolic measurements}

Plasma triglycerides (TG) remained higher (ANOVA for group, $P<0.001$ ) in the Glu27Glu group along the study. Recovery data were significantly lower (Tukey $\mathrm{B}, P<0.05$ ) than exercise values (Figure 1A).

The Glu27Glu group had significantly lower values of plasma glycerol (ANOVA for group, $P=0.047$ ) than the
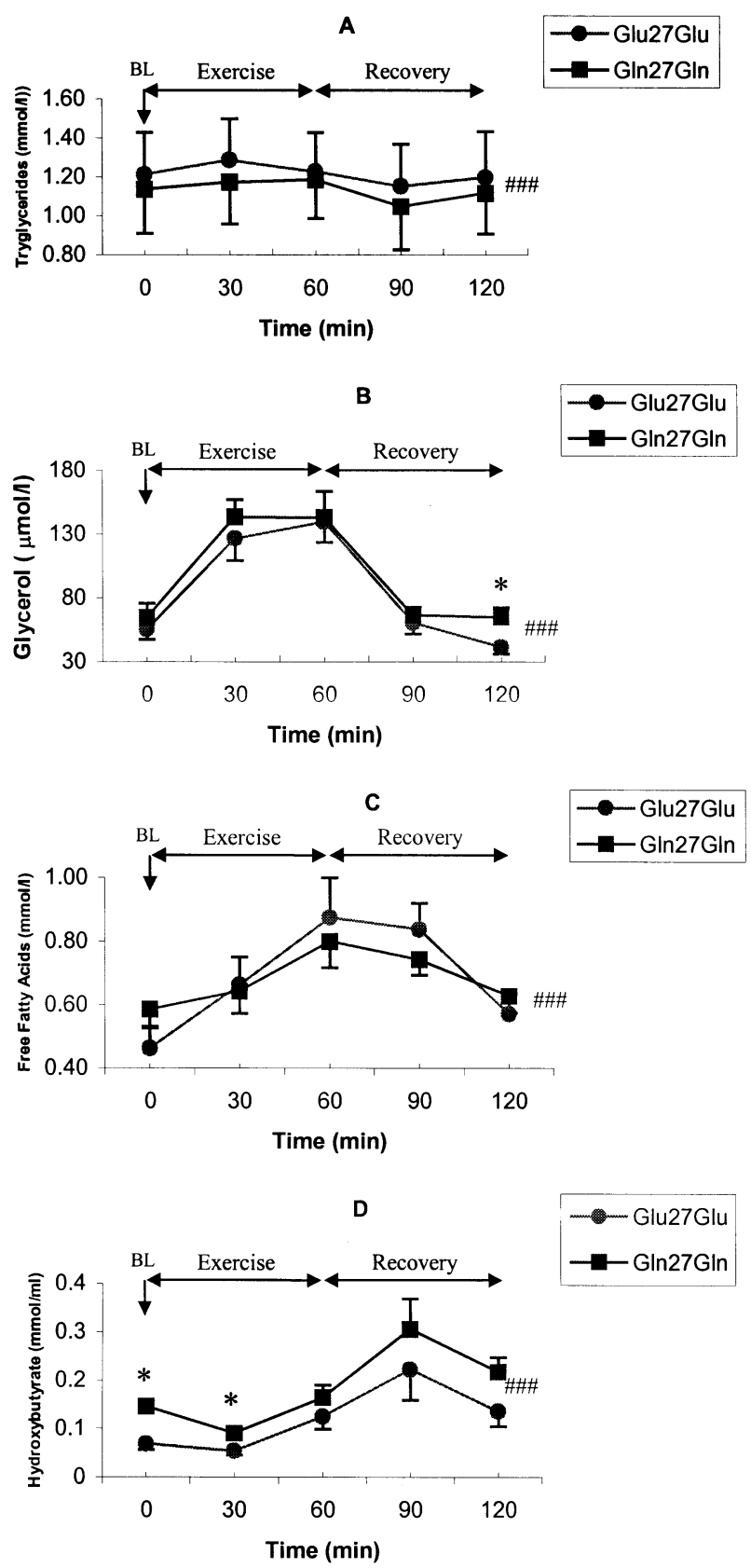

Figure 1 Plasma triglycerides (A), glycerol (B), FFA (C), and hydroxybutyrate (D) in Gln27Gln subjects and Glu27Glu subjects along the

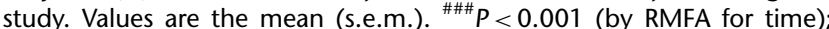
${ }^{*} P<0.05$ (by unpaired Student's t-test). BL, baseline.
Gln27Gln group along the whole study. Exercise values were significantly higher (Tukey $\mathrm{B}, P<0.05$ ) than basal and postexercise values (Figure 1B).

Plasma FFA increased (Tukey B, $P<0.05$ ) with the onset of exercise, and decreased (Tukey $\mathrm{B}, P<0.05$ ) after the exercise (Figure 1C). No differences between groups were detected (ANOVA for group, $P>0.05$ ).

The Glu27Glu group had significantly lower values of plasma hydroxybutyrate (ANOVA for group, $P<0.001$ ) than the Gln27Gln group along the whole study. Recovery time values were significantly higher (Tukey $B, P<0.05$ ) than basal and exercise values (Figure 1D).

Table 2 shows values of plasma glucose, lactate, insulin, leptin and catecholamines throughout the study. Plasma lactate decreased (Tukey B, $P<0.05$ ) with the onset of exercise, whereas glucose recovery values were higher (Tukey $\mathrm{B}$, $P<0.05)$ than exercise values. Insulin decreased with the onset of exercise (Tukey B, $P<0.05$ ) and returned to basal values during the recovery (Tukey $\mathrm{B}, P<0.05$ ), whereas plasma leptin decreased significantly after the exercise (Tukey B, $P<0.05$ ). Noradrenaline was significantly higher during exercise and decreased to basal values during the recovery (Tukey $\mathrm{B}, P<0.05$ ). Although no statistical differences were found between groups in plasma catecholamines throughout the study, noradrenaline tended to be higher in the Glu27Glu group (ANOVA for group, $P=0.090$ ).

Respiratory quotient was significantly higher in the Glu27Glu group than in the Gln27Gln group during the whole study (ANOVA for group, $P=0.046$; Figure 2A).

No group-time interaction was found in any of the measurements along the whole study.

Neither carbohydrate nor protein oxidation differed between groups (Student's unpaired $t$-test, $P>0.05$ ). Fat oxidation was not different between groups both at basal and exercise period, but was significantly lower (Student's unpaired $t$-test, $P=0.048$ ) in the Glu27Glu group than in the Gln27Gln group during the recovery (Figure $2 \mathrm{~B}$ ).

\section{Discussion}

The present data indicate that the ADRB2 Glu27Glu obese women group is different from its Gln27Gln matched group concerning lipid metabolism. Hence, the Glu27Glu group had a lower lipolysis along the study, as assessed by plasma glycerol. In addition, the RQ was significantly higher in the variant Glu27Glu group during the whole study, and its fat oxidation was significantly lower during the recovery. This was supported with the finding that plasma hydroxybutyrate remained lower all along the intervention in the Glu27Glu group.

Recently, it has been shown that Caucasian postmenopausal women bearing the Glu27Glu genotype have higher body weight, BMI and fat mass as compared to the other ADRB2 genotypes. ${ }^{24}$ As the lower $\mathrm{VO}_{2 \max }$ reached by women in such study may be due to their excess of fat mass, our groups were matched for these two criteria. In a Spanish 

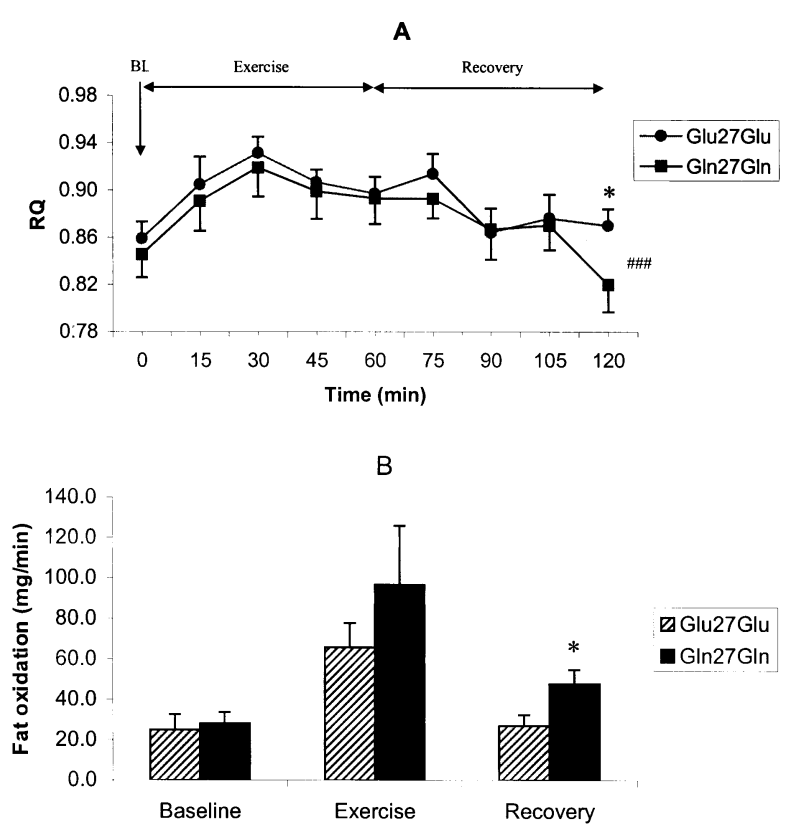

Figure 2 Respiratory quotient (A) during the whole study and fat oxidation ( $\mathrm{mg} / \mathrm{min})$ (B) at baseline, exercise and recovery.

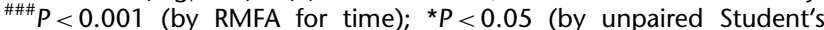
t-test, Glu27Glu vs Gln27Gln).

population, we previously found that obese women who reported to be more physically active in their leisure time and were carriers of the Glu27 allele had higher BMI as compared to non carriers performing the same level of exercise. ${ }^{25}$ Interestingly, Meirhaeghe $e t a l^{16}$ reported that in sedentary men, those carrying the Gln27Gln genotype had higher body weight, BMI and WHR, as compared with Glu27 carriers. In contrast, the risk of becoming obese was not increased in men reporting regular physical activity. Therefore, based on these studies ${ }^{16,25}$ we could conclude that obese individuals with the ADRB2 Gln27Gln genotype may benefit from physical activity to reduce their weight. ${ }^{16}$ This is in line with our findings since lipolysis and fat oxidation during exercise were higher in our Gln27Gln group as compared to the Glu27Glu group, so again, the Gln27Gln genotype (lacking the Glu27 allele) seems to benefit more from exercise. Studies with identical twins would have provided clearer evidence, ${ }^{39}$ but neither twins, nor siblings were found in our obese population, so homozygous Glu27Glu obese women were matched with other group of homozygous Gln27Gln women. This design has also been reported in similar studies. ${ }^{27}$

Longer times of mild exercise would have provided a greater lipolysis, ${ }^{40}$ but $1 \mathrm{~h}$ was a sufficient stimulus, given that glycerol and plasma FFA release into bloodstream increased significantly with the onset of exercise. Moreover, a decrease in plasma insulin and an increase in sympathoadrenal activity are considered the major determinants of 
fat cell lipolysis in exercise, ${ }^{29}$ which was reflected in our study. Recently, it has been reported that homozygous subjects for the Arg allele in amino acid 16 of the ADRB2 had lower levels of FFA when they are physically active. ${ }^{23}$ Given that homozigosity of the Arg16 allele most commonly occurs with the genotype Gln $27 \mathrm{Gln},{ }^{11,19}$ we would expect lower FFA in the Gln27Gln group with exercise in our study. This could explain the profile followed, although no differences were detected between groups.

The higher RQ in the Glu27Glu group suggests that the blend of oxidized fuels during the recovery is poorer in lipid content than it is in the Gln27Gln group. This was confirmed with fat oxidation calculations, which did not differ either at baseline and exercise, but showed a diminished fat oxidation in the Glu27Glu group at recovery time.

Ketogenesis, a marker of fat oxidation, is a key pathway in providing energy to fuel gluconeogenesis. ${ }^{41}$ The fact that plasma hydroxybutyrate was lower in the Glu27Glu group both at basal and during light exercise, suggests that fat oxidation is diminished in these subjects. In this context, circulating lactate remained significantly higher in the Glu27Glu group along the study, which could reflect the search of alternative energy sources different from fat.

In accordance with other studies that found higher triglyceridaemia in subjects bearing the Glu allele, ${ }^{13,19,42,43}$ plasma triglycerides (TG) remained higher in our Glu27Glu group than in the Gln27Gln group throughout the study. On the other hand, the only measured hormone that significantly differed between groups was insulin, which was higher in the Glu27Glu group. This is in line with other studies that reported that the frequency of the Glu27 allele is higher in patients with non-insulin-dependent diabetes mellitus than in non-diabetic subjects. ${ }^{13}$ Similarly, Large et al found that Glu27Glu women had higher fasting plasma insulin level than the other genotypes. ${ }^{11}$ It is believed that resistance to insulin-stimulated glucose uptake with compensatory hyperinsulinemia is the primary culprit in the metabolic syndrome, ${ }^{44}$ which is accompanied by high TG and low HDL cholesterol. ${ }^{45}$ Moreover, high levels of both serum insulin and TG appear to be among the three metabolic variables that closest correlated with obesity in a recent study based on 1010 subjects. ${ }^{46}$ In our study, the higher insulin and TG levels in the Glu27Glu group along the study could lead to future insulin resistance and DM linked to this polymorphism, as previously reported. ${ }^{13}$ Given that Trp64Arg polymorphism in the $\beta 3$-adrenoceptor has been linked to an early onset of NIDDM $^{47}$ and insulin resistance, ${ }^{48}$ we wondered if the increased insulin in the variant Glu27Glu group could be due to a simultaneous presence of the Trp64Arg polymorphism. This possibility was excluded since data from a previous investigation on the same subjects ${ }^{49}$ revealed that there were only two heterozygous Trp64Arg, but in the Gln27Gln group.

A number of recent reviews, ${ }^{50,51}$ have shown that the lipolytic action of the catecholamines is blunted in vivo in obese subjects. Also, a decreased ADRB2 function in the subcutaneous adipocytes of obese adults has been reported. ${ }^{52}$ Although no statistical differences were found between groups in plasma catecholamines throughout our study, noradrenaline tended to be higher in the variant group $(P=0.090)$, suggesting that the exercise released norepinephrine induced lipolysis could be blunted in the polymorphic Glu27Glu group.

These results cannot be attributable solely to a defect in the ADRB2 activation in the Glu27Glu group, since the reesterification of FFA and glycerol into TG, as well as the mechanisms between activation of the adrenoceptors and the breaking down of TG into FFA and glycerol could also be involved. The possibility, that our results are due to a cluster of polymorphisms that have yet to be studied, cannot be excluded. In this line, analysis of homozygous genotypes revealed that the Cys19Cys genotype in the $5^{\prime}$ leader cistron most commonly occurs with Gln $27 \mathrm{Gln} .{ }^{8}$ Since receptor expression was approximately two-fold higher in those bearing the Cys polymorphism, our results could also be attributable to this major expected ADRB2 expression in the Gln27Gln.

In conclusion, the present data suggest that in female obese subjects, both lipolysis and fat oxidation promoted by an acute submaximal exercise intervention appear blunted in the polymorphic Glu27Glu group vs the Gln27Gln group. These results provide useful information on the role of the Gln27Glu polymorphism in the etiology of human obesity and on its subsequent therapy.

\section{Acknowledgments}

We are indebted to Thomas Rau and JL Vizmanos for their valuable counselling in Genetics. Special thanks go to MJ Calasanz and JP Román for their statistical advice. We thank Ana Lorente and Verónica Ciaurriz for the biochemical assays. Gratitude is expressed to Dr J Calabuig and the staff of the University Clinic for their valuable help during the maximal and submaximal trials. Financial support from Línea Especial and Gobierno de Navarra is gratefully recognized. T Macho was supported in part by the Deutsche Akademische Austauschdienst.

\section{References}

1 Sakane N, Yoshida T, Umekawa T, Kogure A, Kondo M. Beta2adrenoceptor gene polymorphism and obesity. Lancet 1999; 353 1976.

2 Reynisdottir S, Wahrenberg H, Carlstrom K, Rossner S, Arner P. Catecholamine resistance in fat cells of women with upper-body obesity due to decreased expression of beta 2-adrenoceptors. Diabetologia 1994; 37: 428-435.

3 Enoksson S, Talbot M, Rife F, Tamborlane WV, Sherwin RS, Caprio S. Impaired in vivo stimulation of lipolysis in adipose tissue by selective beta2-adrenergic agonist in obese adolescent girls. Diabetes 2000; 49: 2149-2153.

4 Schiffelers SL, Saris WH, Boomsma F, van Baak MA. beta(1)- and beta(2)-Adrenoceptor-mediated thermogenesis and lipid utilization in obese and lean men. J Clin Endocrinol Metab 2001; 86: $2191-2199$. 
5 Hall IP. Beta 2 adrenoceptor polymorphisms: are they clinically important? Thorax 1996; 51: 351-353.

6 Green SA, Turki J, Innis M, Liggett SB. Amino-terminal polymorphisms of the human beta 2-adrenergic receptor impart distinct agonist-promoted regulatory properties. Biochemistry 1994; 33: 9414-9419.

7 Green SA, Cole G, Jacinto M, Innis M, Liggett SB. A polymorphism of the human beta 2-adrenergic receptor within the fourth transmembrane domain alters ligand binding and functional properties of the receptor. J Biol Chem 1993; 268: 23116-23121.

8 McGraw DW, Forbes SL, Kramer LA, Liggett SB. Polymorphisms of the $5^{\prime}$ leader cistron of the human beta2-adrenergic receptor regulate receptor expression. J Clin Invest 1998; 102: 1927-1932.

9 Green SA, Turki J, Hall IP, Liggett SB. Implications of genetic variability of human beta 2 -adrenergic receptor structure. Pulm Pharmac 1995; 8: 1-10.

10 Lin RCY, Ericsson JO, Benjafield AV, Morris BJ. Association of beta2-adrenoceptor Gln27Glu variant with body weight but not hypertension. Am J Hypertens 2001; 14: 1201-1204.

11 Large V, Hellstrom L, Reynisdottir S et al. Human beta-2 adrenoceptor gene polymorphisms are highly frequent in obesity and associate with altered adipocyte beta- 2 adrenoceptor function. J Clin Invest 1997; 100: 3005 - 3013.

12 Hellstrom L, Large V, Reynisdottir S, Wahrenberg H, Arner P. The different effects of a Gln27Glu beta 2-adrenoceptor gene polymorphism on obesity in males and in females. J Intern Med 1999; 245: $253-259$

13 Ishiyama-Shigemoto S, Yamada K, Yuan X, Ichikawa F, Nonaka K. Association of polymorphisms in the beta2-adrenergic receptor gene with obesity, hypertriglyceridaemia, and diabetes mellitus. Diabetologia 1999; 42: 98-101.

14 Yamada K, Ishiyama-Shigemoto S, Ichikawa F et al. Polymorphism in the $5^{\prime}$-leader cistron of the beta2-adrenergic receptor gene associated with obesity and type 2 diabetes. J Clin Endocrinol Metab 1999; 84: 1754-1757.

15 Mori Y, Kim-Motoyama H, Ito Y et al. The Gln27Glu beta2adrenergic receptor variant is associated with obesity due to subcutaneous fat accumulation in Japanese men. Biochem Biophys Res Commun 1999; 258: 138-140.

16 Meirhaeghe A, Helbecque N, Cottel D, Amouyel P. Beta2adrenoceptor gene polymorphism, body weight, and physical activity. Lancet 1999; 353: 896.

17 Meirhaeghe A, Helbecque N, Cottel D, Amouyel P. Impact of polymorphisms of the human beta2-adrenoceptor gene on obesity in a French population. Int J Obes Relat Metab Disord 2000; 24: $382-387$.

18 Macho Azcarate T, Marti del Moral A, Martinez Hernandez JA. [Genetic studies of obesity in humans.] Med Clin (Barc) 2000; 115 $103-110$.

19 Ehrenborg E, Skogsberg Ruotolo G, Large V, Eriksson P, Arner P, Hamsten A. The Q/E27 polymorphism in the $\beta_{2}$-adrenoceptor gene is associated with increased body weight and dyslipoproteinaemia involving triglyceride-rich lipoproteins. J Intern Med 2000; 247: 651 .

20 Echwald SM, Sorensen TI, Tybjaerg-Hansen A, Andersen T, Pedersen O. Gln27Glu variant of the human beta2-adrenoreceptor gene is not associated with early-onset obesity in Danish men. Diabetes 1998; 47: 1657-1658.

21 Kortner B, Wolf A, Wendt D, Beisiegel U, Evans D. Lack of association between a human beta-2 adrenoceptor gene polymorphism $(\mathrm{g} \ln 27 \mathrm{glu})$ and morbid obesity. Int J Obes Relat Metab Disord 1999; 23: 1099-1100.

22 Oberkofler H, Esterbauer H, Hell E, Krempler F, Patsch W. The Gln27Glu polymorphism in the beta2-adrenergic receptor gene is not associated with morbid obesity in Austrian women. Int J Obes Relat Metab Disord 2000; 24: 388-390.

23 Meirhaeghe A, Luan J, Selberg-Franks P et al. The effect of the Gly16Arg polymorphism of the beta(2)-adrenergic receptor gene on plasma free fatty acid levels is modulated by physical activity. J Clin Endocrinol Metab 2001; 86: 5881-5887.
24 Moore GE, Shuldiner AR, Zmuda JM, Ferrell RE, McCole SD, Hagberg JM. Obesity gene variant and elite endurance performance. Metabolism 2001; 50: 1391.

25 Corbalán MS, Marti A, Martínez-González MA, Martínez JA. The $27 \mathrm{Glu}$ polymorphism of the $\beta_{2}$-adrenergic receptor gene interacts with physical activity on obesity risk among female subjects. Clin Genet (in press).

26 Morris JN, Hardman AE. Walking to health. Sports Med 1997; 23: $306-332$.

27 Buemann B, Schierning B, Toubro S et al. The association between the val/ala-55 polymorphism of the uncoupling protein 2 gene and exercise efficiency. Int J Obes Relat Metab Disord 2001; 25: 467 - 471.

28 Ranallo RF, Rhodes EC. Lipid metabolism during exercise. Sports Med 1998; 26: $29-42$

29 Galbo H. Exercise Physiology: Humoral function. Sports Sci Rev 1992; 1: 65.

30 Wasserman's principles of exercise testing and interpretation, 2nd edn. Lea \& Febiger: Philadelpphia, PA; 1994.

31 WHO. Technical Report Series no. 894. 2000; i-xii: 1-253.

32 Astrup A. Healthy lifestyles in Europe: prevention of obesity and type II diabetes by diet and physical activity. Public Health Nutr 2001; 4: 499-515.

33 Tai MM, Castillo TP, Pi-Sunyer FX. Thermic effect of food during each phase of the menstrual cycle. Am J Clin Nutr 1997; 66: $1110-1115$

34 Balado D (ed). McArdle, Katch and Katch's exercise physiology, 4th edn. Williams \& Wilkins: Baltimore, Maryland; 1996.

35 Ferrannini E. The theoretical bases of indirect calorimetry: a review. Metabolism 1988; 37: 287-301.

36 Marques-Lopes I, Ansorena D, Astiasaran I, Forga L, Martinez JA. Postprandial de novo lipogenesis and metabolic changes induced by a high-carbohydrate, low-fat meal in lean and overweight men. Am J Clin Nutr 2001; 73: 253-261.

37 Magalini FI, Marcelletti C, Fegiz G, Del Grande G, Mencuccini A. MEDISYSTEM (R) - a modular computer architecture for integrated management of clinical information and images. Evaluation after one year of use in hospital departments. J Clin Comput 1989; 17: 89-98.

38 Boomsma F, Alberts G, van der Hoorn FA, Man in't Veld AJ, Schalekamp MA. Simultaneous determination of free catecholamines and epinine and estimation of total epinine and dopamine in plasma and urine by high-performance liquid chromatography with fluorimetric detection. J Chromatogr 1992; 574: 109-117.

39 Ukkola O, Tremblay A, Bouchard C. Beta-2 adrenergic receptor variants are associated with subcutaneous fat accumulation in response to long-term overfeeding. Int J Obes Relat Metab Disord 2001; 25: 1604-1608.

40 Ahlborg G, Felig P, Hagenfeldt L, Hendler R, Wahren J. Substrate turnover during prolonged exercise in man. Splachnic and leg metabolism of glucose, free fatty acids, and amino acids. J Clin Invest 1974; 53: 1080.

41 McGarry JD, Foster DW. Regulation of hepatic fatty acid oxidation and ketone body production. A Rev Biochem J 1980; 49: 395.

42 Iwamoto N, Ogawa Y, Kajihara S et al. Gln27Glu beta2-adrenergic receptor variant is associated with hypertriglyceridemia and the development of fatty liver. Clin Chim Acta 2001; 314: 85-91.

43 Rosmond R, Ukkola O, Chagnon M, Bouchard C, Bjorntorp P. Polymorphisms of the beta2-adrenergic receptor gene (ADRB2) in relation to cardiovascular risk factors in men. J Intern Med 2000; 248: $239-244$

44 Reaven GM, Lithell H, Landsberg L. Hypertension and associated metabolic abnormalities - the role of insulin resistance and the sympathoadrenal system. New Engl J Med 1996; 334: 374-381.

45 Jeppesen J, Hein HO, Suadicani P, Gyntelberg F. High triglycerides and low HDL cholesterol and blood pressure and risk of ischemic heart disease. Hypertension 2000; 36: 226-232.

46 Ho SC, Chen YM, Woo JL, Leung SS, Lam TH, Janus ED. Association between simple anthropometric indices and cardiovascular risk factors. Int J Obes Relat Metab Disord 2001; 25: $1689-1697$. 
47 Walston J, Silver K, Bogardus C, Knowler WC, Celi FS, Austin S, Manning B, Strosberg AD, Stern MP, Raben N. Time of onset of non-insulin-dependent diabetes mellitus and genetic variation in the beta 3-adrenergic-receptor gene. New Engl J Med 1995; 333: 343.

48 Widen E, Lehto $M$, Kanninen $\mathrm{T}$, Walston J, Shuldiner AR, Groop LC. Association of a polymorphism in the beta 3adrenergic receptor gene with features of the insulin resistance syndrome in Finns. New Engl J Med 1995; 333: 348.

49 Corbalan MS, Marti A, Martinez-Gonzalez MA, Forga L, Martinez JA. The influence of a $\beta_{3}$-adrenergic polymorphism on the risk of obesity is evident in young adults. Int $J$ Obes Relat Metab Disord 2001; 25(Suppl 2): S45.
50 Arner P. Regulation of lipolysis in fat cells. Diabetes Rev 1996; 4: $450-463$.

51 Jensen MD. Lipolysis: contribution of regional fat. A Rev Nutr 1997; 17: 127-139.

52 Arner P. Catecholamine-induced lipolysis in obesity. Int J Obes Relat Metab Disord 1999; 23(Suppl 1): 10-13. 